\title{
Komposisi dan Kontribusi Penerimaan dalam Negeri APBN 1992/1993 Sebuah Ançang-ancang Mandiri
}

\author{
Oleh : Muslich.
}

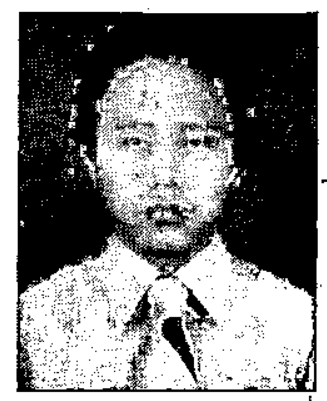

Drs. Musllch, MM. Dllahirkan dl Bariyuwiangl 8 Januarl 1954. Dosen tetap FE. UII Yogyakarta. Lulus SarJana EkonomidIUlltahun 1980. Program. Maglster Manajemen dI.UGM (S2) lulus tahun 1990.

MenjadI Dosen Negerl dlpekerJakan pada FE UII sejak tahun 1981 sampal sekarang.

Mengajar pula dl Program MBA dan BBA dl Institut ManaJemen BIsnis Indonesia (IMBI) dan Widya Utama Yogyakarta tahun 1991-1992.

Penelltlan pada sektor ekonoml a.I : Penelltlan Kualltas Kerajlinan Kullt Manding Bantul Yogyakarta. Kredit Usaha TanI Daerah Sleman Yogyakarta. Peneilltan Pedagang KakI Llma (pedagang. Buku) Kodya Yogyakarta. Study Kelayakan UsahaHuller dil Gunung KIduI Yogyakarta. Beberapa kall menulls dl mass medla balk dl majalah IImlah maupun surat kabar, balk dl Yogyakarta maupun Jakarta.

\section{Pendahuluam}

Pada setiap tahun pemerintah Indonesia dalam rangka melaskanakan Pembangunan Lima Tahunnya senantiasa menyusun Rencana Anggaran dan Belanja Negara atau RAPBN. Di dalamnya tersaji dan terpaparkan unsur-unsur Penerimaan dan Unsur Pengeluaran dalam jangka waktu satu tahunan. Dengan demikian di dalam Anggaran dan Belanja Negara tercermin berapa jumlah penerimaan yang direncanakan diterima dan berápa jumlah pengeluaran yang akan dikeluarlan oleh pemerintah dan Negara.

Unsur penerimaan dari APBN merupakan barometer mengenai potensi sumber pembiayaan yang dapat disediakan oleh pemerintah. Besarnyá unsur penerimaan akan dapat menentukan seberapa besar volume kegiatan pembangunan yang dapat dilaksanákan. Makin besar sumber penerimaan yang dapat diterima makin besar pula volume dan intensitas pembangunan yang dapat dilaksanakan. Sebaliknya semakin kecil 
sumber penerimaan yạng dapat diterima, maka akan semakin kecil volume kegiatan pembangunan yang dapat dijalankan. Sebagaimana kita mengetahui sejak dibukanya Indonesia untuk menerima bantuan Pembiayaan dari negara atau lembaga Internasional luar negeñi, maka unsur-penerimaan dalam APBN selain terdiri atas unsur penerimaan dari dalam negeri juga ada unsur penerimaan yang berasal dari luar negeri: Tapi sejak dini sudah ditegaskan bahwa unsur dari luar - negeri tersebut hanya sebagai faktor atau unsur pelengkap saja. Namun demikian, dalám perkembangannya bahwa bantuan yang berasal dari luar negeri ini baik secara relatif maupun secara absolut jumlahnya makin besar, hampir mendekati 4 kali lipat. Ini adalah beban yang cukup besar di masa datang.

Oleh karena sifatnya pelengkap, maka kita berharap agar pinjaman dari luar negeri ini tidak akan membebani terlalu berat bagi generasi mendatang. Dan seiring dengan kemajuan ekonomi kita maka perannya diharapkan akan makin mengecil di masa datang. Dan ini nampak mulai kelihatan, terutama pada tahun-tahun terakhir. Hal ini terjadi lantaran dalam waktu 'yang hampir bersamaan telah terlihat bahwa unsur Penerimaan lain yang berasal dari dalam negeri menunjukkan kontribusi yang makin besar dan cukup mendominasi. Misalnya dari sub sektor Pajak Penghasilan, Pajak Pertambahan - Nilai, Penerimaan Migas dan lain-lain. Kita lihat misalnya pada APBN 10 tahun terakhir terlihat ada pergeseran komposisi dan peran pada beberapa sub sektor Penerimaan Dalam Negeri. Di satu pihak peran Bantuan Luar Negeri makin cenderung menurun, tapi di pihak lain peran Penerimaan Dalam Negeri khususnya dari sub sektor Pajak cenderung makin besar kontribusinya bahkan terlihat makin dominan. Oleh karena itu dalam tulisan ini hendak dicoba untuk menelusuri pergeseran sektor-sektor penerimaan APBN yang telah dan akan terjadi 10 tahun terakhị ini, dan. bagaimana yang seharusnya ditempuh di masa yang akan datang.

Pergeseran Komposisi Penerimaan APBN

Semenjak dua atau tiga tahun terakhir. dan terlebih lagi pada saat memasuki tahun anggaran 1992/1993 ini, jika dilihat dari angka-angka RAPBN tahun 1990/1991 dan tahun 1991/1992 yang lalu serta angka-angka RAPBN 1992/1993 maka terkesan bagi kita bahwa bahwa dan negara Indonesia akan memulai ancangancangnya untuk bisa memperlihatkan gejala kemadiriannya dalam aspek pebiayaan pembangunan. Hal ini nampak apabila kita perhatikan dari besamya Penerimaan APBN, khususnya dari sektor Penerimaan Pembangunan maka gejalanya makin menunjukkan gejala penurunan, dari Rp 11.289,5 milyar pada tahun 1990/1991, menjadi Rp 10.371,5 milyar dan $\mathrm{Rp} 9.600,2$ milyar pada tahun 1991/1992 dan 1992/1993. Penurunan angka-angka ini didominasi oleh penurunan Bantuan Program, yakni dari jumlah Rp 2.885,3 milyar pada tahun 1990/1991 menjadi hanya Rp 1.537,3 milyar pada periode 1991/1992 dan 1992/1993. Sementara Penerimaan dan Bantuan Proyek tidak mengalami penurunan, malahan meningkat dari $\mathbf{R p}$ 8.404,2 menjadi Rp 8.834,0 dan Rp $9.099,0$ milyar pada periode yang sama. Kita kétahui bahwa Penerimaan Pembangunan berasal dan diperoleh dari Bantuan Luar Negeri. Dan apabila dilihat 
dari gejalanya maka secara total jumlahnya sedikit mengalami penurunan. Penurunan yang sedikit ini lebih disebabkan karena di satu pihak dalam waktu yang hampir bersamaan telah diimbangi dengan kenaikan yang cukup tinggi pada Penerimaan Bantuan Proyek.

Akan tetapi jika dilihat dari komposisi Penerimaan pembangunan (Luar Negeri) terhadap seluruh penerimaan APBN maka sejak tiga tahun terakhir ini kontribusi penerimaan Luar Negeri terlihat makin mengecil. Hal ini dapat kita artikan bahwa peranannya terhadapiseluruh penerimaan telah mulai menurun dari sekitar $26,3 \%$; $20,5 \%$ pada tahun 1990/1991, 1991/1992, dan diprediksi menjadi hanya $17,10 \%$ pada tahun $1.992 / 1993$, kembali seperti semula pada tahun 1984/1985 dan pada tahun $1985 / 1986$ yang hanya berkisar antara $15 \%-18 \%$. dan tahun 1992/1993.

Ini menunjukkan bahwa dominasi Penerimaan Dalam Negeri makin besar terhadap seluruh penerimaan untuk membiayai pembangunan terutama pada periode 2 tahun terakhir ini.

\section{Migas dan Non Migas}

Perlacakan lebih lanjut tentang Penerimaan Dalam Negeri APBN antara lain dapat kita lakukan melalui telaah perbandngan antara Penerimaan Migas dan Penerimaan Non Migas.

Semenjak masa boom migas sekitar 1984 sampai dengan 1986 memang Indonesia sebagai salah satu negara pengekspor migas ketika itu benar-benar ketiban rezki dan merupakan masa yang paling menguntungkan dilihat dari perolehan sumber pembiayaan pembangunan lantaran dominasi dari Migas ketika itu.

Tabel : 1 Komposisi Penerimaan APBN 1984/1985 S/D 1992/1993 (dalam trilyun-Rupiah)

\begin{tabular}{|c|c|c|c|c|c|c|c|c|c|c|c|}
\hline & Tahun - & & Pen.Pemb. & . & $\%$ & & Pen.DN & & $\%$ & Total & \\
\hline & $1984 / 1985$ & - & 3,478 & 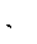 & 17,9 & & 15,905 & & 82,05 & 19,383, & \\
\hline i & $1985 / 1986$ & & 3,572 & & 15,65 & & 19,252 & & 84,34 & 22,825 & ${ }^{\circ}$ \\
\hline & 1986/1987 & $\because$ & $5,7 \ddot{5} 2_{2}$ & & 26,27 & & 16,140 & & 73,72 & 21,892 & \\
\hline . & $1987 / 1988$ & & 6,158 & & $22 ; 84$. & & 20,803 & & 77,15 & 26,961 & \\
\hline & $1988 / 1989$ & $\begin{array}{ll}- \\
-\end{array}$ & $9,990^{\prime}$ & & 30,27 & & 23,004 & & 69,72 & 32,995 & - \\
\hline & $1989 / 1990$ & & 9,429 & & 24,70 & & 28,739 & · & 75,29 & 38,169 & \\
\hline & $1990 / 1991$ & & 11,289 & & 26,33 & & 31,563 & $\cdot$ & 73,66 . & 42,873 & \\
\hline & $1991 / 1992$ & & 10,371 & & 20,52 & & 40,184 & & 79,48 & 50,555 & 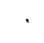 \\
\hline & $1992 / 1993$ & & 9,600 & . & 17,10 & & 46,508 & & 82,89 & . $\quad 56,108$ & \\
\hline
\end{tabular}

Sumber: Nota Keuangan 1992/1993; APBN 1991/1992 dan RAPBN 1992/1993

Sébaliknya peran Penerimaan Dalam Negeri terlihat makin besar dan makin dominan dari seluruh penerimaan. Hal ini dapat kita perhatikan kontribusinya dari sebesar $75 \%$ kemudian $73 \%$ dan 79,48 $\%$ dan $82,89 \%$ pada periode $1989 / 1990$ kemudian 1990/1991; tahun 1991/1992
Ketika total Penerimaan Dalam Negeri dari APBN disusun sebesar Rp 15.905,5 milyar pada tahun $1984 / 1985$, kontribusi Penerimaan Migas' memegang peran sebesar 65,6 \% dari seluruh Penerimaan Dalam Negeri. Kemudian menyusul sebesar $57,9 \%$ dan $39,3 \%$ pada tahun 
1985/1986 dan 1986/1987. Kemudian mengalami sedikit kenaikạn dan penurunan peran berturut-turut sebesar $48,3 \%, 41,4$ $\%, 39,2 \% 44,825,15 \%$ dan $37,4 \%$ pada tahun 1987/1988, 1988/1989, 1989/1990, 1990/1991 dan 1991/1992. Dan diprediksikan bahwa pada tahun 1992/1993 ini penerimaan Migas hanya berperan sebesar $30,0 \%$ saja. Tetapi komposisi tersebut hanya berperanan di bawah $50 \%$. Terlebih lagi jika kita mengingat bahwa harga migas pada masa mendatang dalam APBN tahun 1992/1993 diperkirakan mengalami penurunan dan' telah dipatok dengan harga US $\$ 17$ per barelnya, maka peranan migas masih akan dibawah $50 \%$.

Sementara peran Penerimaan Non Migas pada periode 1984 - 1992 terlihat makin meningkat, seperti pada tabel 2 berikut ini:
Penerimaan Dalam Negeri cenderung meningkat diatas atau lebih dari $50 \%$.

Gejala seperti itu memang harus dan perlu terus dipacu untuk ditingkatkan di masa-masa yang akan datang. Jika tidak, kita khawatir akan terjebak terlalu dalam pada keinginan dan keharusan bergantung pada pinjaman luar negeri.

Selain itu kita menyadari bahwa sumber migas dalam waktu yang tidak terlampau lama akan segera habis, dan selama waktu belum habisnya Migas ini, kita harus sudah mempersiapkan dan memantapkan benar atas upaya peningkatan penerimaan dari non migas ini, baik itu pada volume ekspor non migas maupun pada penerimaan non migas lainnya, seperti Pajak: Penghasilan (PPh), Pajak Pertambahan Nilai (PPn), dll.

Tabel 2 : Komposisi Penerimaan Dalam Negeri (dalam Milyar rupiah) dalam 1984/1985 - 1992/1993

\begin{tabular}{lrrrrrr}
\hline Tahun & Migas & $\%$ & Non Migas & $\%$ & Pen Dlm Neg. \\
\hline $1984 / 1985$ & $10.429,9$ & & 65,6 & $5.475,6$ & 34,4 & $15.905,5$ \\
$1985 / 1986$ & $11.144,4$ & & 57,9 & $8.108,4$ & 42,1 & $19.252,8$ \\
$1986 / 1987$ & $6.337,6$ & & 39,3 & $9.803,0$ & 60,7 & $16.140,6$ \\
$1987 / 1988$ & $10.047,2$ & & 48,3 & $10.756,1$ & 51,7 & $20.803,3$ \\
$1988 / 1989$ & $9.527,0$ & 41,4 & $13.477,3$ & $-58,6$ & $23.004,3$ \\
$1989 / 1990$ & $11.252,1$ & 39,2 & $17.487,7$ & 60,8 & $28.739,8$ \\
$1990 / 1991$ & $10.783,2$ & 44,8 & $.20 .800,4$ & 55,2 & $31.583,6$ \\
$1991 / 1992$ & $15.008,8$ & 37,4 & $25.175,2$ & 62,6 & $40.184,0$ \\
$1992 / 1993$ & $13.947,5$ & 30,0 & $32.560,9$ & 70,0 & $46.508,4$ \\
\hline
\end{tabular}

Sumber : Nota Keuangan 1992/1993; APBN 1991/1992 dan RAPBN 1992/1993

Kenaikan tersebut terjadi dari $34,4 \%$ pada tahun 1984 naik menjadi 42,1 pada tahun 1985. Kemudian naik lagi $60,7 \% \mathrm{~s} / \mathrm{d} 70,0$ $\%$ pada periode $1986-1992$. Dengan perkataan lain bahwa dominasi Penerimaan Non Migas dalam kontribusinya terhadap
PPh, PPn dan Harapan Mandiri.

'Seperti kita ketahui dalam tabel 3 berikut, bahwa Penerimaan Non Migas, khususnya PPh dan PPn, ternyata merupakan pengandil yang cukup besar sejak tahun $1984 \mathrm{~s} / \mathrm{d}$ tahun 1992. 
Tabel 3 Kontribusi PPti dan PPn Terhadap Total Penerimaan Pajak selama tahun 1984/1985 - 1992/1993 (dalam milyar Rp.)

\begin{tabular}{lrrr}
\hline Tahun & PPh + PPn. & $\%$ & Total Pen.Pajak \\
\hline $1984 / 1985$ & $2.999,0$ & 88,5 & $3.385,6$ \\
$1985 / 1986$ & $4.629,7$ & 91,5 & $5.065,9$ \\
$1986 / 1987$ & $5.170,6$ & 91,8 & $5.629,8$ \\
$1987 / 1988$ & $6.063,8$ & 89,7 & $6.735,3$ \\
$1988 / 1989$ & $8.454,7$ & 90,6 & $12.361,8$ \\
$1989 / 1990$ & $11.324,4$ & 91,6 & $12.361,8$ \\
$1990 / 1991$ & $13.339,8$ & 92,9 & $14.356,5$ \\
$1991 / 1992$ & $16.245,0$ & 92,5 & $17.556,1$ \\
$1992 / 1993$ & $21.962,2$ & $93,9,23.367,3$ \\
\hline
\end{tabular}

Sumber : Nota Keuangan 1992/1993; Warta Ekonomi No. 37/11//13 Jan. 1992:

Tempo No. $46 \mathrm{Th}$. XXI - 11 Jan. 1992

Dilihat dari seluruh Penerimaan Pajak maka PPh dan PPn memberikan kontribusi dari $88,5 \%$ pada tahun $1984 / 1985 \mathrm{~s} / \mathrm{d}$ 93,9\% pada tahun 1992/1993. Cukup dominan memang peran PPh dan PPn ini. Dari kontribusi tersebut apabila kemudian kita melihatnya dari seluruh Penerimaan Non Migas terhadap'seluruh Penerimaan
Dalam Negeri (minus non Pajak), maka kontribusi Penerimaan Pajak terlihat telah dan akan memberikan kontribusi sebesar antara $24,6 \%$ pada tahun $1984 / 1985$ meningkat menjadi s/d 62,7 \% pada tahun 1992/1993. Hal ini dapat kita lihat pada tabel 4 sebagai berikut :

Tabel : 4 Kontribusi Penerimaan Pajak dan Migas Terhadap Penerimaan Dalam Negeri (minus penerimaan non pajak), dalam periode 1984/1985 - 1992/1993 (dalam milyar rupiah).

\begin{tabular}{lrrrrr}
\hline Tahun & Pen.Pajak & $\%$ & Pen.Migas & $\%$ & Pen Dlm Neg \\
\hline $1984 / 1985$ & $3.385,6$ & 24,6 & $10.429,9$ & 75,4 & $13.815,5$ \\
$1985 / 1986$ & $5.065,9$ & 11,5 & $11.144,4$ & 89,5 & $16.210,3$ \\
$1986 / 1987$ & $5.629,8$ & 47,0 & $6.337,6$ & 53,0 & $11.967,4$ \\
$1987 / 1988$ & $6.735,3$ & 40,1 & $10.047,2$ & 59,9 & $16.782,5$ \\
$1988 / 1989$ & $9.326,6$ & 49,5 & $9.527,0$ & 50,5 & $18.853,6$ \\
$1989 / 1990$ & $12.361,8$ & 52,5 & $11.527,0$ & 47,5 & $23.613,9$ \\
$1990 / 1991$ & $14.356,5$ & 57,4 & $10.783,2$ & $42,6$. & $25.139,7$ \\
$1991 / 1992$ & $17.556,1$ & 54,0 & $15.008,8$ & 46,0 & $32.564,9$ \\
$1992 / 1993$ & $23.367,3$ & 62,7 & $13.947,5$ & 37,3 & $37.314,8$ \\
\hline
\end{tabular}

Sumber : Nota Keuangan 1992/1993; APBN 1991/1992 dan RAPBN 1992/1993

Warta Ekonomi no. 37/1U/13 Januari 1992.

Tempo no. 46 th. xxi 11 Januari 1992. 
Dari angka kontribusi Pajak terhadap Penerimaan Dalam Negeri dapatlah dikatakan makin membesar dan makin melampaui penerimaan Migas, yakni dari $11,5 \%$ pada tahun $1995 / 1986$ menjadi $62,7 \%$ pada tahun $1992 / 1993$. Sementara penerimaan Migas terlihat makin menurun dari $75 \%$ pada tahun $1984 / 1985$ menjadi hanya37,3 \% pada tahun 1992/1993. Hal ini jelas cukup membanggakan dan memberikan rasa optimis bagi kelangsungan pembangunan kita yang tangguh dan kuat di masa datang, sekalipun jika Migas pada saatnya nanti habis, namun sumber pembiayaan yang berasal dari dalam negeri yang lainnya kita prediksikan masih akan dapat kita katakan cukup tangguh karena dukungan dari sub sektor pajak. Karena itu agar penggalian dapat dilaksanakan secara optional, maka kiranya diperlukan suatu perencanaan dan pelaksanaan serta pengendaliannya dapat dilaksanakan lebih ketat lagi. Selain itu supaya potensi sumber pajak yang benarbenar tersedia dapat kita gali secara optimal, layak dan adil. Sehingga kemampuan dan kemandirian negara Indonesia dalam membiayai pembangunannya yang sekarang mulai kelihatan tersebut dapat menapakkan kakinya, sebagai tahap tinggal landas dan terlebih lagi pada saat hendak memasuki tahapan Pemnbangunan Jangka Panjang kedua mendatang,' demi kelangsungan kesinambungan Pembangunan Indonesia dalam janga panjang.

Keberhasilan ekonomi dengan prediksi pertumbuhan ekonomi yang cukup tinggi di masa datang ini, jelas akan memberikan harapan dan prospek atas Penerimaan Dalam Negeri dalam jumlah yang makin besar. Di samping itu Penerimaan di sektor Pajak yang dapat kita andalkan sebagai menyangga Penerimaan Dalam Negeri diharapkan makin besar seiring dengan gerak pertumbuhan ekonomi yang makin besar tersebut. Sehingga kita dapat memperlihatkan yang makin besar pada tahap-tahap pembangunan berikutnya.

\section{Penutup}

Dari gejala makin membengkaknya peranan Penerimaan Dalam Negeri terhadap seluruh Penerimaan APBN pada dekade terakhir dan yang akan datang, maka hal ini telah dan akan menunjukkan sinyal-sinyal kemandirian pada sumber pembiayaan yang makin kita andalkan untuk membiayai pembangunan memasuki tahap tinggal landas dan memasuki tahapan Jangka Panjang kedua yang akan datang.

Peranan, kontribusi dan dominasi sektor Penerimaan Dalam Negeri akan makin besar jika di lain pihak percepatan serta kemajuan ekonomi bangsa dan rakyat Indonesia secara nasional akan makin luas dan pesat pertumbuhannya.

Oleh karena itu yang cukup penting untuk kita perhatikan adalah : bagaimana aspek penggunaan sumber-sumber pembiayaan itu dapat mencapai suatu taraf efisensi dan efektifitas yang cukup tinggi. Peluang pemborosan, kebocoran yang mungkin terjadi di masyarakat akan dapat kita usahakan untuk ditekan seminimal mungkin. Untuk itu peran kontrol dan pengawasan yang lebih ketat menjadi sesuatu yang penting. Díi sinilah kuncinya agar volume pembangunan yang dijalankan dengan sumber pembiayaan dari Dalam Negeri akan dapat didayagunakan secara optimal. Inilah harapan kita semua. 


\section{Daftar Pustaka}

1. Nota Keuangan dan RAPBN 1991/1992

2. Nota Keuangan dan RAPBN 1992/1993

3. Majalah Warta Ekonomi No. 37/IIV/ 13 Januari 1992
4. Majalah Tempo No. 46 Tahun XXI 11 Januari 1992

5. Pidato Presiden, pada saat menyampaikan Pengantar RAPBN, di DPR RI, Jakarta 1992.

से 
